\title{
Escaping Capability Traps through Problem Driven Iterative Adaptation (PDIA)
}

Matt Andrews, Lant Pritchett, Michael Woolcock

CID Working Paper No. 240

June 2012

(C) Copyright 2012 Andrews, Matt; Pritchett, Lant; Woolcock, Michael, and the President and Fellows of Harvard College
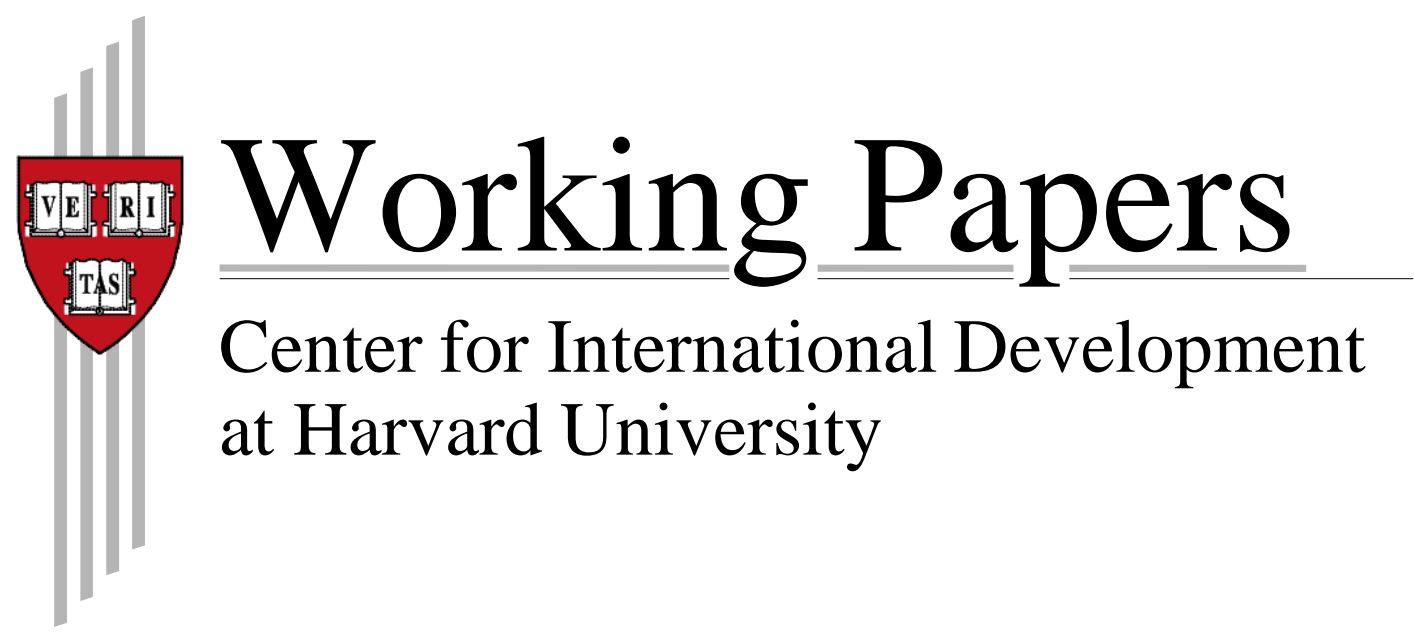


\title{
Escaping Capability Traps Through Problem Driven Iterative Adaptation (PDIA)
}

\author{
Matt Andrews, Lant Pritchett and Michael Woolcock ${ }^{1}$
}

June 15, 2012

\begin{abstract}
Many reform initiatives in developing countries fail to achieve sustained improvements in performance because they are merely isomorphic mimicry - that is, governments and organizations pretend to reform by changing what policies or organizations look like rather than what they actually do. The flow of development resources and legitimacy without demonstrated improvements in performance, however, undermines the impetus for effective action to build state capability or improve performance. This dynamic facilitates _capability traps“ in which state capability stagnates, or even deteriorates, over long periods of time despite governments remaining engaged in developmental rhetoric and continuing to receive development resources. How can countries escape capability traps? We propose an approach, Problem-Driven Iterative Adaptation (PDIA), based on four core principles, each of which stands in sharp contrast with the standard approaches. First, PDIA focuses on solving locally nominated and defined problems in performance (as opposed to transplanting pre-conceived and packaged -best practicell solutions). Second, it seeks to create an _authorizing environment' for decision-making that encourages _positive deviance “ and experimentation (as opposed to designing projects and programs and then requiring agents to implement them exactly as designed). Third, it embeds this experimentation in tight feedback loops that facilitate rapid experiential learning (as opposed to enduring long lag times in learning from ex post -evaluation\|). Fourth, it actively engages broad sets of agents to ensure that reforms are viable, legitimate, relevant and supportable (as opposed to a narrow set of external experts promoting the -top downll diffusion of innovation).
\end{abstract}

\footnotetext{
${ }^{1}$ Andrews and Pritchett are with Harvard University‘s Kennedy School of Government; Woolcock is with the Development Research Group, World Bank. The corresponding author is Matt Andrews, Assistant Professor, Harvard Kennedy School, 116 Rubenstein, 79 John F. Kennedy Street, Cambridge, MA, 02138, USA. Email addresses for correspondence: matt_andrews@hks.harvard.edu, lant_pritchett@hks.harvard.edu and mwoolcock@worldbank.org. This paper is part of a broader research agenda at the Harvard Kennedy School's Center for International Development supported by WIDER. The views expressed in this paper are those of the authors alone, and should not be attributed to the respective organizations with which they are affiliated. Helpful comments from participants at various seminars and conferences are gratefully acknowledged.
} 


\section{Introduction}

Some building is easy. Development projects have, by and large, been successful at building physical stuff: schools, highways, irrigation canals, hospitals and even building the buildings that house government ministries, courts and agencies. But some building is hard. As anyone with experience in development knows, building the capabilities of the human systems is hard. That applies to the human system called -the state.\| Getting the human beings in the state to use the physical stuff available to produce the flows of improved services (learning in schools, water to farmers, cures for patients) that lead to desirable outcomes for citizens has proven much more difficult.

There is no shortage of small and large scale examples. One of us was recently asked to review the design of an education project in an African country; it was the sixth in a string of large projects supporting education in this country. The project documents described the deplorable state of the capability of the ministry of education to even implement the projectmuch less to autonomously define problems, gather and analyze information, make decisions based on analysis, and implement their own decisions. Therefore the project proposed funding to build more schools but also significant funding to build the capability of the ministry. But of course all of the five previous projects over a span of twenty years had also sought to build both schools and ministry capability, and had succeeded at only one of those objectives.

This dynamic also often characterizes -policy reform\|: a government succeeds in passing laws or creating new boxes in organizational charts or declaring new administrative processes, but these -reforms\|l are frequently not implemented or used. Andrews (2011), for example, documents the case of the adoption of public financial management reforms in Africa, showing how the higher level and surface processes changed (e.g., how budgets were written and new accounting techniques were adopted) but how the core processes determining how money was actually spent remained impervious to reform. Perhaps the most spectacular large-scale contemporary example is that the richest and most powerful nation in the history of humankind has just spent a decade-and enormous amounts of blood (almost 2000 dead) and treasure (over half a trillion dollars) — attempting to (re)build state capability in a very small and poor South Asian country. The United States is now committed to leaving by 2014, almost certainly leaving behind a state less capable than what Afghanistan had in the 1970s. 
Why has building state capability been so hard? In past work we argued that development interventions — projects, policies, programs—create incentives for developing country organizations to adopt _best practices ' in laws, policies and organizational practices which look impressive (because they appear to comply with professional standards or have been endorsed by international experts) but are unlikely to fit into particular developing country contexts. ${ }^{2}$ Adapting from the new institutionalism literature in sociology ${ }^{3}$, we suggested that reform dynamics are often characterized by _isomorphic mimicry`—the tendency to introduce reforms that enhance an entity's external legitimacy and support, even when they do not demonstrably improve performance. These strategies of isomorphic mimicry in individual projects, policies and programs add up to _capability traps': a dynamic in which governments constantly adopt -reforms ll to ensure ongoing flows of external financing and legitimacy yet never actually improve. The fact that the -development communityll is five decades into supporting the building of state capability and that there has been so little progress in so many places (obvious spectacular successes like South Korea notwithstanding) suggests the generic -theory of changell on which development initiatives for building state capability are based is deeply flawed.

How might countries escape from capability traps? This is the question we begin answering in the current article. We first revisit the argument about how and why countries and development partners get trapped in a cycle of reforms that fail to enhance capability (indeed, may exacerbate pre-existing constraints). We posit that capability traps emerge under specific conditions which yield interventions that (a) aim to reproduce particular external solutions considered _best practice` in dominant agendas, (b) through predetermined linear processes, (c) that inform tight monitoring of inputs and compliance to the plan', and (d) are driven from the top down, assuming that implementation largely happens by edict. ${ }^{4}$

\footnotetext{
${ }^{2}$ See Pritchett and Woolcock (2004); Pritchett, Woolcock and Andrews (2010); and Andrews (2011).

${ }^{3}$ See the classic work of Dimaggio and Powell (1983).

${ }^{4}$ An important paper by Denizer, Kaufmann and Kraay (2011: 2), however, shows that implementation is actually of crucial importance to project quality. On the basis of an examination of 6000 World Bank projects, these authors conclude that -measures of project size, the extent of project supervision, and evaluation lags are all significantly correlated with project outcomes, as are early-warning indicators that flag problematic projects during the implementation stage... measures of World Bank project task manager quality matter significantly for the ultimate outcome of projects. II
} 
A second section suggests that capability traps can be avoided and overcome by fostering different types of interventions. In direct counterpoint to the four conditions above, we propose that efforts to build state capability should (i) aim to solve particular problems in local contexts, (ii) through the creation of an _authorizing environment‘ for decision-making that allows _positive deviation` and experimentation, (iii) involving active, ongoing and experiential learning and the iterative feedback of lessons into new solutions, doing so by (iv) engaging broad sets of agents to ensure that reforms are viable, legitimate and relevant—i.e., politically supportable and practically implementable. We propose this kind of intervention as an alternative approach to enhancing state capability, one we call Problem Driven Iterative Adaptation (PDIA). We emphasize that PDIA is not so much _new' thinking as an attempt at a pragmatic and operational synthesis of related arguments articulated in recent years by an array of scholars and practitioners of development working in different sectors and disciplines.

\section{I) Capability traps in the effort to build state capability}

Development interventions can be usefully analyzed at three social levels (Figure 1): agents, at the front line and in leadership positions; organizations inhabited by agents; and the environment or ecosystem of organizations. Within each category, Figure 1 also illustrates the poles of behaviors (for agents and organizations) or conditions (within eco-systems).

Frontline workers decide daily between mere compliance with rules (or even negative deviations) and positive performance-driven actions. Leaders and managers choose between using their positions to pursue narrow private or organizational gain or to create new public value within and through the organizations they run. Organizations manage how and from whence they derive the legitimacy needed to survive and thrive, balancing isomorphic pressures to comply with external expectations of what they should look like and the challenge of demonstrating performance regardless of appearance.

At the systemic level, fields of organizations that include suppliers, producers, regulators, funders and consumers determine implicit and explicit ways of evaluating change and novelty. Systems could reward compliance with fixed agendas of what is considered appropriate and 
_right“ practice at one extreme, or look to the simple demonstration of improved functionality at another. A second tension also plays out at this systemic level, affecting the space created for novelty: closed systems constrain novelty and do not allow new approaches to emerge, while open systems facilitate novelty (see Brafman and Beckstrom 2006).

Figure 1.Tensions playing out at different levels of engagement in development

\section{Ecosystem for organizations}

Closed

Agenda

Conformity

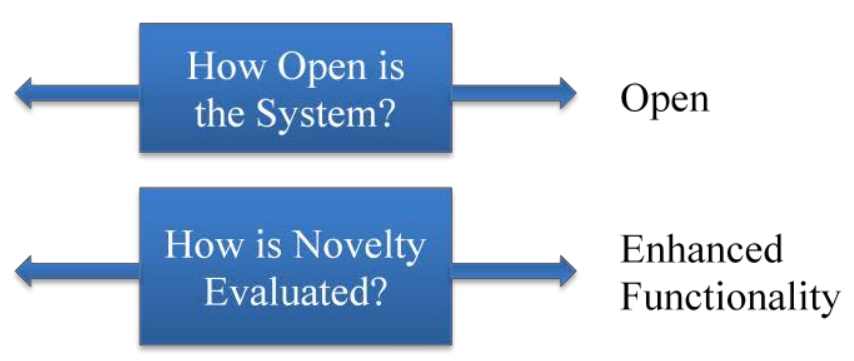

Strategies for

Organizational

Legitimation

within the

Ecosystem
Demonstrated

Success

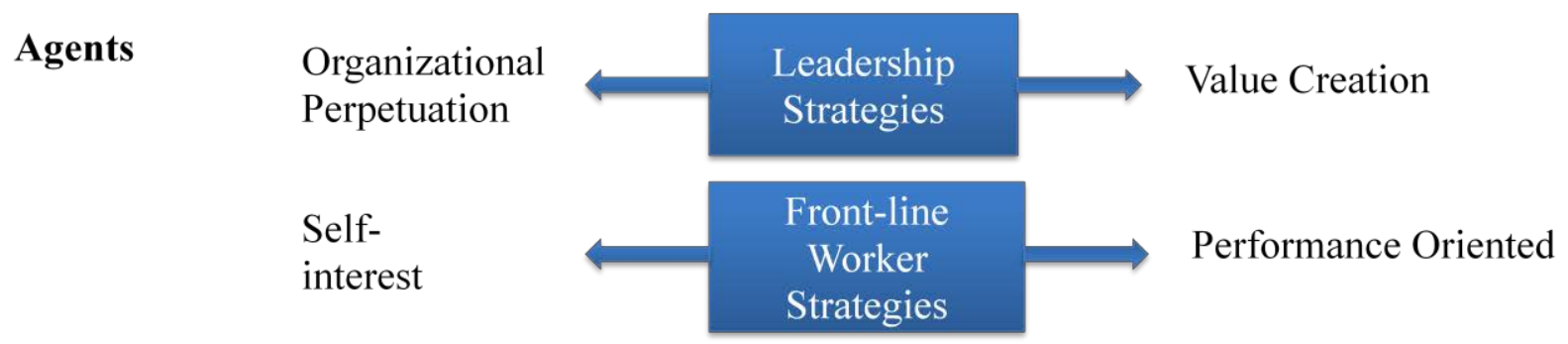

Source: Pritchett, Woolcock and Andrews (2010)

Countries find themselves in capability traps when conditions at each level foster decisions and behaviors on the left side of Figure 1; this can create a low level equilibrium. When the ecosystem for organizations evaluates novelty based on agenda-conformity rather than enhanced functionality, then the space for novelty is closed and subsequently cascades (Carlile and Lakani 2011). In such situations, organizations adopt -isomorphic mimicryll strategies of looking like successful organizations: leaders seek organizational survival, continued budgets and rents by complying with external standards of legitimacy instead of encouraging new ideas, 
products and solutions, while front line workers choose routine compliance (at best; at worst, often corruption or malfeasance) over concern for the customers, clients and citizens they serve. The difficult reality is that once the -capability trap\| is sprung there is no incentive—and often no possibility—-for any one organization or leader or front-line agent to break out.

Much of the literature on capacity and corruption focuses on the role agents play in such situations. It is common to hear statements like: -The country would progress if only it had less corrupt leaders and more capable and concerned civil servants. $\|^{5}$ Blaming agents in this way suggests a personalized rather than systemic perspective on why countries remain poor-one which is obviously false. This perspective has yielded efforts to discipline agents and limit the opportunities for rent seeking via organizational interventions like civil service, judicial and public finance reform. Organizations in developing countries have been required to accept such interventions for decades now. As Rodrik (2008: 100) notes, -institutional reform promoted by multilateral organizations such as the World Bank, the International Monetary Fund, or the World Trade Organization (WTO) is heavily biased towards a best-practice model. It presumes it is possible to determine a unique set of appropriate institutional arrangements ex ante, and views convergence toward those arrangements as inherently desirable. II Such apparent convergence is undertaken to ensure continued legitimacy with, and support from, the international community. A common example is procurement reform: laws requiring competitive bidding are a procedure that many development organizations require their client countries to adopt in order to receive financial support. Such requirements, for instance, were among the first demands international organizations made in post war Liberia, Afghanistan and Sudan. They are intended to constrain corruption, discipline agents, and bring an air of formality and legitimacy to the way governments operate.

We hold, however, that these reform initiatives are now, ironically, among the drivers of capability traps in developing countries, because they create and reinforce processes through which global players constrain local experimentation—while at the same time facilitating the

\footnotetext{
${ }^{5}$ For example, Greg Mills from South Africa‘s Brenthurst Foundation recently noted that Malawi would be doing better -If only Malawians were luckier with their leaders. II See his article in the Malawi Democrat: http://www.malawidemocrat.com/politics/long-fingers-in-the-warm-heart-of-africa/
} 
perpetuation of dysfunction ${ }^{6}$. The conditions we allude to have characterized the politics and processes of international development since at least the 1980s, a period when government reform became an important dimension of development work. At that time, many external development organizations began tying their funds to such reforms, as well as using conditions in structural adjustment and other budget financing initiatives (e.g. -sector widell approaches). This has made it increasingly difficult for a developing country to receive external financial assistance without committing to change their government and market structures. The commitments must be made ex ante and promise reform that is open to visible evaluation in relatively short time periods, such that external development partners have something tangible to point to when justifying the disbursement of funds. In this relationship, development partners have to accept proposed reform ideas and sign off on their attainment. This role has fed the creation of various scripts defining acceptable types of reform. The World Governance Indicators, for instance, guide countries in choosing governance reforms by illustrating what is considered legitimate. Similarly, the Doing Business indicators inform what reforms are needed to the institutions connecting government and the private sector, while mechanisms such as Public Expenditure and Financial Accountability (PEFA) indicators focus developing countries on conforming with characteristics ostensibly reflecting "good international practices ... critical ... to achieve sound public financial managementll (PEFA 2006: 2).

Such scripts, we argue, have essentially closed the space for novelty in the development system, imposing narrow agendas of what constitutes acceptable change. Developing countries and organizations operating within them are regularly evaluated on their compliance with these scripts, and the routine and generalized solutions they offer for establishing -good governancell, facilitating private sector growth, managing public finances, and more. Organizations like finance ministries or central banks gain legitimacy by agreeing to adopt such reforms, regardless of whether they offer a path towards demonstrated success in a particular context. Leaders of the organizations, for their part, can further their own careers by signing off on such interventions. Their agreement to adopt externally mandated reforms facilitates the continued flow of external

\footnotetext{
${ }^{6}$ Our argument at the institutional and organizational level is similar to that made by Nicolas van de Walle (2001) about -structural adjustment\| in Africa. He points out that engagement of governments in the process of reform - even when patently insincere on the part of governments and when reforms were not implementedbrought external legitimacy. This contributed to the puzzle of the region with the worst development outcomes having the most stable governments.
} 
funds, which can further various public and private interests. Front line workers ostensibly required to implement these changes are seldom part of the conversation about change, however, and thus have no incentive to contribute ideas about how things could be improved.

The example of procurement reform in countries like Liberia and Afghanistan is a good instance of this dynamic in action. PEFA indicators and United Nations models of good procurement systems tout competitive bidding as a generic solution to many procurement maladies, including corruption and value for money concerns. Competitive bidding regimes are introduced through laws, as are the creation of independent agencies, the implementation of procedural rules and the introduction of transparency mechanisms. These various_inputs` are readily evaluated as _evidence‘ that change is in effect. Countries are rewarded for producing these inputs; government entities and vendors subjected to such mechanisms are assumed to simply comply. The result is a top-down approach to building procurement capacity (and beyond) in these governments, through which external role players impose themselves on local contexts and crowd out potential contributions local agents might make to change. These local agents have every incentive to treat reforms as signals, adopting external solutions that are not necessarily politically accepted or practically possible in the local context. But when the conditions are wrong, this mimicry signaling is the easiest route to achieving legitimacy, especially when the pathway to creating real value and facilitating actual improvement in performance is uncertain, risky and potentially contentious. Local agents have little incentive to pursue improved functionality in such settings, especially when they are rewarded so handsomely for complying with externally mandated _forms‘ (appearances).

\section{II) Escaping capability traps and actually building state capability}

The emphasis on form (what organizations _look like') over function (what they actually _do') is a crucial characteristic of the capability trap facing many developing countries. The challenge of escaping this trap therefore involves focusing on improved government functionality as the key to improved state capability. The basic message must be that interventions are successful if they empower a constant process through which agents make organizations better performers, 
regardless of the forms adopted to effect such change. The politics of this re-focusing recommendation are obviously complex. They require, for instance, challenging perspectives about when and how to tie development funding to reform results, asking if external agents and solutions can build local state capabilities, and clarifying whether and how local agents and solutions should play a greater role in their own development. They may also entail adopting reforms that, at least initially, powerful critics can deride as unprofessional (_promoting nonbest-practice solutions`), inefficient (_reinventing the wheel`), even potentially unethical (_failing to meet global standards‘). These are far from idle concerns.

This section does not address these political narratives. Instead, it offers some potential ideas and practical suggestions for how the development process might look if political discourse did call for a change in the approach to reforming governments and building state capability. As noted above, we fully recognize that others have voiced related concerns across various sectors in a range of forums; these previous articulations, however, have mostly stopped at critique rather than moving on to propose concrete, supportable, implementable alternatives. To this end, our alternative draws on and synthesizes related themes that get at the common core idea: learning organizations‘ (Senge 1990 [2006]),_projects as policy experiments` (Rondinelli 1993),_adaptive versus technical problems‘ (Heifetz 1994),_positive deviance (Marsh et al 2004; Pascale, Sternin and Sternin 2010), institutional_monocropping`versus _deliberation‘ (Evans 2004), _experimentation“ (Mukand and Rodrik 2005; Manzi 2012),_good-enough governance‘ (Grindle 2004),_democracy as problem solving‘ (Briggs 2008), the _sabotage of harms ‘ (Sparrow 2008), _second-best institutions‘ (Rodrik 2008), _interim institutions“ (Adler, Sage and Woolcock 2009), =upside down governance‘ (Institute for Development Studies 2010), just-enough governance‘ (Levy and Fukuyama 2010), =best fit‘ strategies (Booth 2011), _principled incrementalism‘ (Knaus 2011), and_experiential learning‘ (Pritchett, Samji and Hammer 2012), among others.

Our proposed approach, which we call Problem-Driven Iterative Adaptation (PDIA), is based on four core principles. We are at pains to stress that these are broad principles which are consistent with a wide range of implementation options rather than a specific single program or approach. That is, what we are proposing is not itself yet another -solution\| that countries need to implement or a recipe they should follow. Rather, we believe these are the elements of 
approaches that will create enhanced possibilities of success in an array of sectors and can be implemented in a variety of modalities and country contexts.

The four elements, to be amplified below, stress that reform activities should

(i) aim to solve particular problems in particular local contexts via

(ii) the creation of an _authorizing environment‘ for decision-making that encourages experimentation and _positive deviance ${ }^{{ }^{7}}$, which gives rise to

(iii) active, ongoing and experiential (and experimental) learning and the iterative feedback of lessons into new solutions, doing so by

(iv) engaging broad sets of agents to ensure that reforms are viable, legitimate and relevant—-that is, are politically supportable and practically implementable.

We now address each of these items in turn.

\section{(i) The importance of solving problems, not selling solutions}

Efforts to build state capability should begin by asking -what is the problem? II instead of -which solution should we adopt? || Focusing on prevailing problems is the most direct way of redressing the bias to externally prescribed forms towards internal needs for functionality; it ensures that problems are locally defined, not externally determined, and puts the onus on performance, not compliance. It provides a window onto the challenge of building state capability, forcing agents to assess the ambiguities and weaknesses of incumbent structures, to identify areas where these need to be broken down and de-institutionalized, and to look for better ways of doing things.

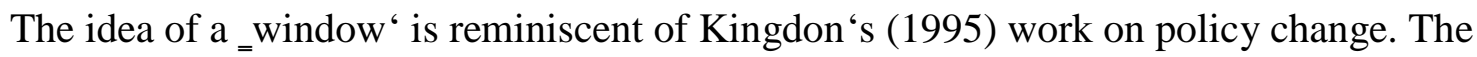
many applications of his _multiple streams“ theory show that problems commonly bring an array of policy and institutional issues onto the change agenda. ${ }^{8}$ Faced with problems they cannot ignore, agents across the social and political spectrum become aware of structural weaknesses they usually do not consider. This awareness often becomes the basis of coalition building across

\footnotetext{
${ }^{7}$ The precise meanings and origins of the terms _authorizing environment` and _positive deviance ‘ are provided below. They come from different literatures (the first from public administration, the second from nutrition) but we have found it fruitful to bring them together.

${ }^{8}$ See Barzelay and Gallego (2006); Guldbrandsson and Fossum (2009); and Ridde (2009).
} 
networks, where agents at different positions are drawn together to deal with a common concern (Zakocs 2006; see also Pires 2011). Problems also generate action and change from these communities, given the common argument that -[i]nstitutional change and improvement are motivated more by knowledge of problems than by knowledge of success\| (Cameron 1986: 67).

Not all problems foster such attention and motivation, however. Valéry Ridde (2009) shows, for instance, that health care reformers in Burkina Faso were quite inattentive to the problem of unequal access in the country. He offers various reasons for this, including the lack of widely shared measures of access and inequality. Without such measures, -verbal gymnastics\| allowed different stakeholders to hold varying views about the issue, some even believing it had been solved by past initiatives (Ridde 2009: 944). His observations support Kingdon`s argument that _issues ‘ or factual_conditions“ have to be politically and socially constructed to gain attention as _problems‘. This involves raising the visibility of issues through spectacular focusing events' (such as crises), the use of statistical indicators, or manipulation of feedback from previous experiences.

Initiatives to build state capability can focus on problems by facilitating this kind of construction‘. This could involve using use tools like the _5-why technique‘ or Ishikawa diagrams. ${ }^{9}$ These serve to de-construct problems, identify root causes and help agents reflect on contextual inadequacies. The 5-why technique pushes agents to identify a problem and then answer _why ${ }^{\varsigma}$ it is a problem five times. The rationale is that agents typically focus on issues and need to think beyond these to specify the problem that could motivate change. A seasoned development expert, for instance, might say that her problem relates to the lack of a particular form' of government — or externally mandated best practice—-but will be forced to reflect on the functional challenge when asked repeatedly ${ }_{=}$why ${ }^{6}$ this matters, and for whom. Imagine the following:

- $\quad$ The problem is that we get a D on the PEFA procurement indicator, because we do not have a law requiring competitive bidding across government. $\|$

- Why does it matter? -Without this law there is an incentive not to use competitive bidding in procurement deals.॥

\footnotetext{
${ }^{9}$ See Ishikawa and Loftus (1990); Serrat (2009); and Wong (2011).
} 
- Why does it matter? -Without this incentive, most procurement deals are currently done through sole source methods.\|

- Why does it matter? -Sole source methods can increase corruption and lead to higher procurement costs and lower quality.॥

- Why does it matter? -We have evidence that many procurement deals have been overly costly and goods are poorly provided.॥

- Why does it matter? -High cost, low quality procurement is undermining the provision of key services across government.\|

\section{Figure 2. Breaking problems down, so that they drive to solutions}

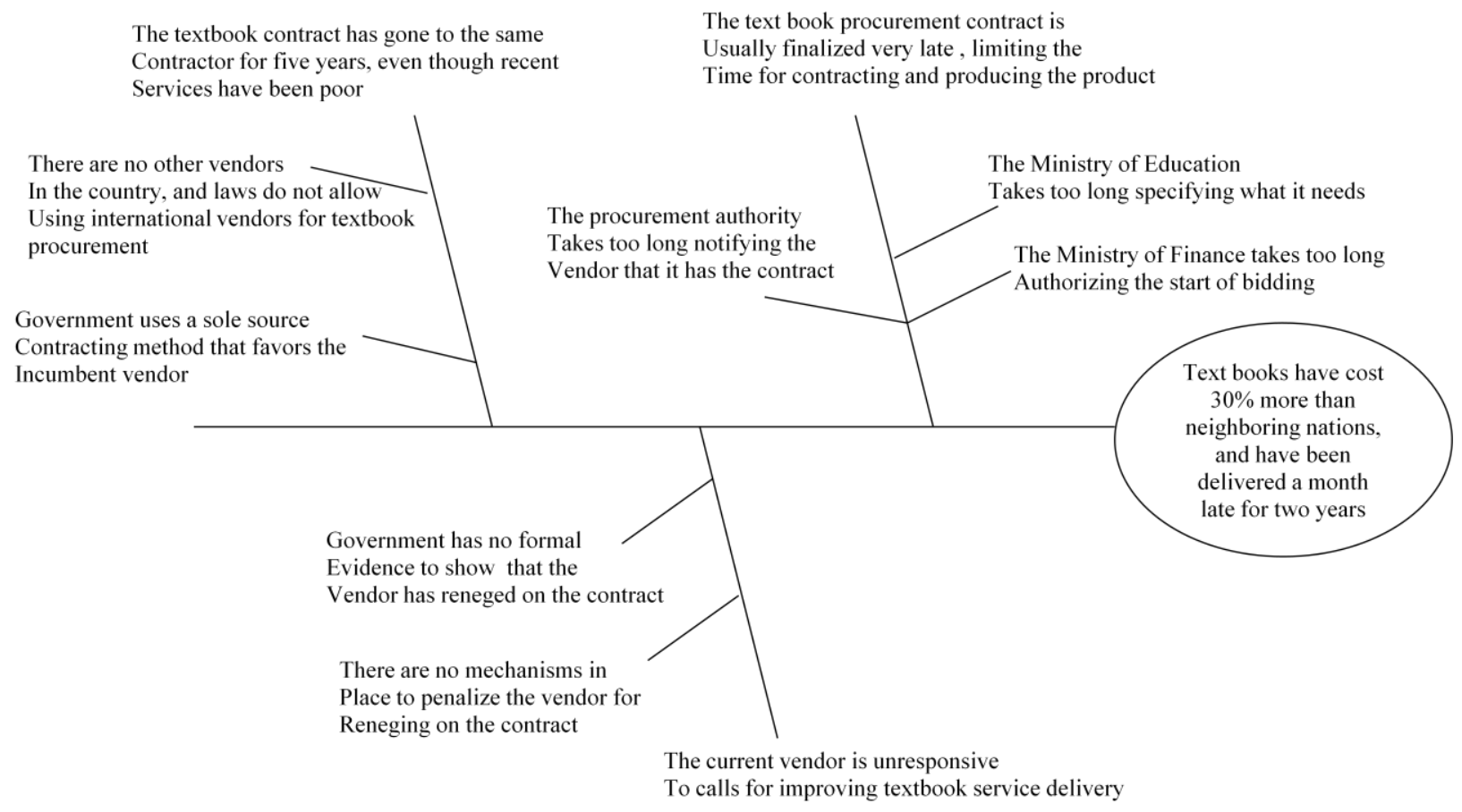

This kind of specification engenders a focus on the high cost and low quality of procurement across government, which is a functional problem of performance. Contrast this to the starting point where the emphasis was on introducing an externally defined _best practice' law to mandate competitive bidding. In shifting the emphasis towards a concern for improved functionality, this kind of process uncovers the real challenges of building capability in 
development. In this case the challenge is not to adopt a new law but to improve the cost and quality of procurement. This is a much more complex problem but the one that needs solving and, crucially, the one that is unlikely to be addressed by simply mandating the use of competitive bidding. Problem-focused processes can get agents to work through the complexity of these problems and identify possible entry points for solutions. Cause and effect exercises can help in this respect, ensuring problems drive the search for solutions. As an example, Figure 2 shows a potential Ishikawa analysis of the proposed problem.

Problems always have multiple causes, which a well-constructed problem focus helps emphasize. Reflecting this, Figure 2 shows how the procurement problem alluded to earlier might be framed and broken down to garner attention and empower a local process of finding solutions. The problem effect is specified at the right, for a particular sector, using data that helps stimulate attention. It is then de-constructed into potential causes and sub-causes, with three major_branches‘ illustrated_reflecting problems in the contracting process, the contracting law and the vendor itself. The issue of sole sourcing contracting is mentioned as a potential subcause, but is one of many such issues and not the focal point of engagement. When local agents are taken through such exercises they become invested in solving the problem, focused on the many potential entry points to start addressing them, and disabused of the notion that there is any one easy externally mandated solution.

When external agents provoke such processes they communicate the intention to provide an open space for novelty and an emphasis on improved functionality as the basis of evaluating reform. The focus on problems also incentivizes organizations to emphasize their performance, and encourages contributions from leaders and front-line workers to work for change. Many argue that agents only mobilize such contributions when prompted by problems, actively participating in change -only when they are able to frame the grievances of aggrieved constituencies, diagnose causes, [and] assign blamell (Snow and Benford 1992: 150). All of these influences involve a shift towards the right hand side of Figure 1—and out of the capability trap.

(ii) The importance of 'authorizing environments' for decision-making that encourage experimentation and 'positive deviance' 
Problem-driven interventions facilitate an escape from capability traps most effectively when they point to -feasible remedial action [that] can be meaningfully pursued $\|$ in the search for solutions (Chan 2010: 3). In this respect, and to be genuinely useful, problems must offer local agents a pathway to find solutions. We do not believe immediate solutions are needed in these situations, given that agents who see the complexity of real problems are seldom likely to accept the mirage of one-best-way solutions. Even if they do, given isomorphic pressures, we strongly advise against closing the space for novelty by providing or imposing easy answers; even if these answers have value, they are unlikely to address all of the problem dimensions needing attention. If completely new to a context, they are also likely to lack the political acceptance and everyday capacity required to work effectively. As such, external agents may possess potential answers but those_answers' must still be experimented with through a process that empowers the search for -technically viable solutions to locally perceived problems\| (Greenwood, Suddaby and Hinings 2002: 60).

In thinking of what such process should look like, we are reminded of theoretical arguments about how policy and institutional solutions often emerge; as a puzzle, over time, given the accumulation of many individual pieces. Modern versions of such a perspective are commonly called incrementalism or gradualism, and attributed primarily to Lindblom (1959), who famously referred to these processes as _muddling through‘. The approach holds that groups typically find“ institutional solutions through a series of small, incremental steps, especially when these involve _positive deviations ${ }^{610}$ from extant realities. One might start addressing the problem shown in Figure 2 by gathering evidence of the textbook vendor's contractual violations, for instance, or building an informal database of when textbooks were delivered.

Such steps are relatively cheap and have the prospect of early success, or quick wins. The blend of cheapness and demonstrable success characterize positive deviations and are important in contexts where change encounters opposition, which is usually the case with government

\footnotetext{
${ }^{10}$ The notion of _positive deviance` in development comes from important research on nutrition in poor communities in Vietnam (see Marsh et al 2004), where some children, despite the desperate physical conditions in which they lived, were nonetheless found to be relatively quite healthy. Seeking an explanation, researchers discovered that the parents of the relatively healthy children were routinely defying community norms about the „proper' way to feed and raise children. These parents, for example, provided their children with several small meals each day rather than one or two large ones; continued to feed their children even when the children had diarrhea; and added sweet-potato greens, a low status food, to the children's rice. On the broader implications of the power of positive deviance` for innovation and reform, see Pascale, Sternin and Sternin (2010).
} 
reforms in developing (and developed) countries. The small steps also help flush out contextual challenges, including those that emerge in response to the interventions themselves. Facilitating such positive deviations, through incremental steps, is especially important in uncertain and complex contexts where reformers are unsure of what the problems and solutions actually are and lack confidence in their abilities to make things better.

=Muddling through' like this does not mean being muddled in the search for change options. Instead, it implies taking a gradual approach to addressing particular problems. In reflecting on this, Bonnie McCay (2002: 368) describes_muddling through` as -a go-slow, incremental approach to problem solving.\| Given this, one would expect incremental reforms to be focused on specific problems and the contextual realities in which these fester. This kind of focus ensures that actions taken in the name of development are what Richard Rose (2003: 20) calls _relevant', or -politically acceptable and within the resources of government.ll The focus on problems helps to build political support, with incremental reform gains consolidating it. The awareness of factors that are causing problems ensures that the chosen solutions are possible, given contextual constraints. Stepwise reforms contribute to building capacity and loosening these constraints over time.

Incremental reforms focused on addressing problems frequently result in hybrid combinations of elements that work together to get the job done. Various authors have described the path to such solutions as bricolage (Dacin, Goodstein and Scott 2002: 50; see also Campbell 2004: 65), or the process by which internal agents _make do ' with resources at hand to foster new (or hybrid‘) structures and mechanisms. ${ }^{11}$ The final product thus contrasts with what Ostrom (2008) calls -optimal\| solutions embodied in external ideas of _right rules` or _one-best-way‘ or best practice“ reforms. As argued, we believe the imposition of such -optimall solutions is a main reason why novelty is constrained in development. The process of positive deviance through bricolage is, in contrast, only possible when novelty is encouraged and rewarded within the authorizing environment ${ }^{12}$ within which key decisions are made. It is a process that helps organizations escape capability traps but must be accommodated by system-wide mechanisms

\footnotetext{
${ }^{11}$ See Mair and Marti (2009). Pritchett, Samji and Hammer (2012) deploy similar language in calling for measures in development programming that facilitate -crawling the design spacel-that is, allowing specific project design elements in particular contexts to emerge as a result of pragmatic explorations for best-fit solutions within the range of possible options.

12 The notion of _authorizing environments “-the delimited organizational domains over which managers have formal decision-making authority_comes from Moore (1995).
} 
that allow non-linear, frustrating (sometimes even contentious) processes of change that are liable to produce idiosyncratic (perhaps odd-looking) solutions. In Figure 2‘s example, for instance, the government might end up proposing a continued sole source textbook procurement mechanism because of a deficient set of potential vendors, but take practical steps to improve the timing of contracts and provide community-level inspections of vendor performance. This is like choosing a slow and odd-looking camel to help one ride through the desert, in lieu of a much faster and more impressive looking horse, given the camel's relevance in its context. It is the kind of decision that reformers make as a result of positive deviance and experimentation, but will always be difficult to _sell' to outsiders who did not muddle through with them, and whose primary metric of success or _rigor‘ is the extent to which a given option complies with a known global _best practice‘ (_professional‘, _expert`) standard.

\section{(iii) The importance of active learning mechanisms and iterative feedback loops}

A problem-driven, stepwise reform process can thus help countries escape from capability traps. This kind of process typifies change in the cooperative structures studied by authors like Elinor Ostrom. ${ }^{13}$ Drawing from such experiences, we argue that positive deviance and experimentation has its greatest impact when connected with learning mechanisms. These ensure the dynamic collection and immediate feedback of lessons about what works and why. McCay references such mechanisms in noting that -[e]fforts to learn and the capacity to adapt ... contribute to the emergence of effectivell solutions in cooperatives. ${ }^{14}$ We note further that this learning is active, happening in the process of real-world experimentation. In referencing such, Ostrom argues that -[t]he process of choice ... always involves experimentation $\|^{15}$ because $-[\mathrm{i}] \mathrm{t}$ is hard to find the right combination of rules that work in a particular setting\|; as such, one has to -try multiple combinations of rules and keep making small adjustments to get the systems working well. $\|^{16}$

Active learning through real-world experimentation allows reformers to learn a lot from the _small-step“ interventions they pursue to address problems (or causes of problems). They learn, for instance, about contextual constraints to change in general, how specific interventions

\footnotetext{
${ }^{13}$ McCay (2002: 368). This approach is exemplified in Ostrom (2005, 2008).

14 Ibid.

${ }^{15}$ Ostrom (2008: 47).

${ }^{16}$ Ostrom (2008: 49).
} 
work (or not), and how these interventions interact with other potential solutions. This facilitates bricolage, with lessons becoming part of the landscape of knowledge and capacities _at hand' from which new arrangements emerge in resource constrained settings. ${ }^{17}$ Some call this -trying out solutions\| (Baker and Nelson 2005: 334) while others refer to it as the continuous testing of new combinations of ideas. The lessons learned in such experimentation are dynamic and make the biggest difference when immediately incorporated into the design discussions about change. In this respect the learning mechanism differs significantly from traditional monitoring and evaluation mechanisms that focus on compliance with a linear process of reform and allow lessons‘ only at the end of a project.

This kind of experimentation and learning is also very different from the field experiments used in randomized trials. ${ }^{18}$ The experimentation we refer to does not involve (always) performing a scientific experiment where the context is suspended and the intervention (by construction) is not allowed to change or vary over the life of the experiment. Rather, it is about trying a real intervention in a real context, allowing on-the-ground realities to shape content in the process. This is also not about proving that specific ideas or mechanisms universally _work' or do not work. Rather, it is about allowing a process to emerge through which attributes from various ideas can coalesce into new hybrids. This requires seeing lessons learned about potential combinations as the key emerging result. The necessary experimentation processes require mechanisms that capture lessons and ensure these are used to inform future activities.

Using the procurement reform example shown in Figure 2, one might think of the first step as experimentation around an intervention intended to show the possibility of positive gain and which yields lessons for next steps. Information about the timing of textbook deliveries might be collected to contribute a database of vendor performance, for instance, helping foster state capabilities to oversee contracts. The collection process could be bound by time and location, focused on a set of districts and a period of just one month. In this period monitors would work daily with teams going out to record when textbooks were delivered, constantly transcribing lessons about which information sources were most reliable, which kinds of

\footnotetext{
${ }^{17}$ Dorado, 2005; Garud and Karnøe, 2003; Mair and Marti, 2009.

${ }^{18}$ For a discussion of the distinction between _experimentation“ and _experiments` in learning about development, see Pritchett (2011) and Pritchett, Samji and Hammer (2012).
} 
questions yielded information quickest, and so forth. The lessons would be fed back to collection teams on an ongoing basis and these teams would be empowered to adjust their methods as the lessons suggested; perhaps focusing on select sources instead of others. The goal would be to allow front line workers and their leaders to find new solutions that improved organizational performance, in due course yielding greater state capability and functionality regardless of form.

\section{(iv) The importance of broad engagement for assuring viability, legitimacy and relevance}

The discussion should make it apparent that we do not believe that building the state's capability for implementation —or development in general—happens exclusively or even predominantly from the top-down. We hold, rather, that change primarily takes root when it involves broad sets of agents engaged together in designing and implementing locally relevant solutions to locally perceived problems. Our argument draws on literatures about institutional entrepreneurship and the importance of distributed agency in the process of change and development.

Many articles in the literature on institutional entrepreneurship start by noting the problematic paradox of embeddedness. This asks how agents embedded in institutional mechanisms can simultaneously find and introduce changes to these mechanisms. ${ }^{19}$ This paradox offers a particular challenge to those who believe change happens from the top-down in societies, where the most powerful ministers or managers push through radical reforms. Essentially, these powerful agents or elites are commonly considered the most embedded in their contexts, and thus are often the least likely to perceive the need for change, to have access to ideas for change, or to risk their interests in pressing for change. In contrast, agents at the periphery_or front line - are less embedded in extant rules, which is partly why they also benefit less from them. Their low embeddedness makes them more open to criticizing incumbents and to entertain change; but they lack the power to make it happen.

Given such thinking, change is only possible if something bridges the agents with power to those with ideas. At its most simple, this could involve a direct or third party link between a

\footnotetext{
${ }^{19}$ Carlile and Lakhani (2011) refer to this as the -novelty-confirmation-transformation II cycle and point out that organizations need both -confirmation $\|$ mechanisms that reinforce organizational continuity and coherence but also some way of recognizing, evaluating, and incorporating novelty.
} 
central leader and front line agent. Such a bridge could open the elite to an alternate awareness of their reality and spur a process of entrepreneurship, through which multiple agents combine to define and introduce change in their contexts. These can be organizations or individuals. They connect over time - directly and indirectly_in networks that facilitate transitions from one rules system to another. Different agents have different functional roles in these networks: some provide power and others bring awareness of problems; some supply ideas or resources, while others act as connectors or bridgers. Change comes out of their interactions, not through their individual engagements.

Consider, for example, the importance of connecting the technical head of the procurement bureau implied in Figure 2 to political heavyweights protecting established vendors` interests. Consider also the need to involve field-level officers and school principals who manage procurement transactions, receive textbooks, and have face-to-face interactions with suppliers. This last group is commonly called de-concentrated or distributed agents and is often ignored in state capability interventions or seen as passive targets of change. Andrea Whittle and colleagues note that this is a major omission, -because an institutional template that is not enacted by all members of an organizational field would invariably fail to become an institution at all\| (Whittle, Suhomlinova and Mueller 2011: 552). They argue that any kind of change, including by implication state capability building for development, requires -the involvement, interaction and conjoint activity of multiple actors $\|$ and especially -the more mundane and less prominent, but nevertheless essential, activities of _others' in the institutional work associated with emergent institution-building\| (p. 553). These _others‘ need to be considered because they are also subject to questions of institutional embeddedness. If institutionalized rules of the game have a prior and shared influence on these agents, why should they be expected to change simply because some leaders tell them to?

A host of new institutional scholars emphasize the importance of fostering broad engagement in the process of institutional change and institution building. Multiple entrepreneurs and distributed agents come to implement new institutions through a process that promotes -understanding, using, and mastering\| them (Jin, Kim and Srivastava 1998: 231). Such processes can be conceptualized in light of Greenwood, Suddaby and Hinings ‘ (2002) influential model of =Theorizing Change‘. They suggest that institutional adjustment typically emerges from a process that begins with jolts but passes through a series of five stages, with the last two titled 
diffusion, and re-institutionalization. The details of this model are not important for this article. What does matter is that the model suggests an extreme limit where change processes in the stages preceding diffusion are characterized by narrow, top-down engagement. Diffusion demands broad support for change which is not attained through narrow hierarchical processes. This idea is reinforced in research showing that higher levels of decision centrality in institutional change processes yield lower rates of intra-organizational diffusion (Jin, Kim and Srivastava 1998). In contrast, higher rates of participation in change decisions produce greater rates of diffusion.

Such effects are amplified where the organization or field undergoing change is large, deconcentrated and informal, and where distributed agents co-inhabit multiple other fields that foster heterogeneous interests and cognitions in those targeted for change. Diffusion is extremely difficult under such conditions and is further undermined by an overly-centralized approach to change. One will find that many agents in the heterogeneous, de-concentrated group will not implement the adopted changes under such conditions. They cannot be forced to do so and will not do so voluntarily because they do not share the understanding that change is needed or that the prescribed solutions are appropriate.

We argue that these are the realities of many contexts in which state-building initiatives are introduced. Narrowly engaged change processes in such contexts exacerbate capability traps, giving front line workers and even indirectly-involved leaders a message that their concerns and value creation ideas are not welcome. We advocate, therefore, for the adoption of convening and connection mechanisms that allow broader engagement in designing, experimenting and diffusing reforms intended to strengthen states. Convening' typically involves bringing groups of leaders together with key implementers to craft local experiments and solutions (Dorado 2005), while _connection“ involves ensuring second and third degree interactions with frontline workers who will ultimately have to implement final changes (Andrews, McConnell and Wescott 2008). These processes allow and encourage agents to move from left to right in Figure 1, escaping capability traps and moving into a context where organizations demand inspired, informed and concerned contributions from their people.

\section{III) Contrasts and similarities}


The main contrast of PDIA would be with the dominant_big development ‘ efforts of mainstream development organizations such as bilateral donors and the World Bank. These organizations are full of amazingly dedicated and intelligent people, but these agents are themselves often locked into ecosystems and organizational practices beyond their control. That this leads to problems with effective implementation of Bank projects has long been identified and discussed (at least since the Wapenhans Report of 1992) but it is very difficult to solve, in part because certain organizational stakeholders have the power to veto actual or potential changes.

This dynamic leads mainstream development organizations to be extremely effective at some types of development activities and much less good at others. There are two types of activities that are easily supported and are likely to lead to success; hence by no means have the World Bank (or donors more generally) been widespread failures, as is often the caricature. First, if a task really requires a logistical' solution-e.g., the scaling up of a technologically known solution that does not involve high implementation intensity in operation — then donor projects nearly always succeed. ${ }^{20}$ One should not lose sight of the basic fact that on many standard indicators of well-being, development has been a massive success, such as the expansion of schooling or the -millions saved\| through expansion of vaccinations or simple public health interventions (Levine 2004). In nearly every physical dimension of access - to roads, sanitation, schools, electricity — the approach has been a resounding, unqualified success (Kenny 2011).

Second, if a task really requires less government intervention then the donors' actions have often been effective, since scaling the state back out of certain things that were both misguided about cause-effect relationships and beyond the implementation capability of governments was desirable and possible. For instance, many governments, through a variety of ideological commitments, policy mis-steps and macroeconomic shocks, backed themselves into rationing foreign exchange. This was, by and large, a disaster, as it had both economic and organizationally perverse consequences. Hence _at a stroke` or _policy implementation light` reforms that eliminated this rationing through devaluation and liberalization were truly _win-win and could be implemented via external conditionality and financial support.

${ }^{20}$ On this point see Pritchett and Woolcock (2004). 
Where the mainstream` approach founders, however, is precisely when it confronts activities like building organizational and state capability, since these tasks require (a) enormous numbers of discretionary decisions and (b) extensive and intensive face-to-face transactions to be carried out by (c) implementing agents needing to resist large temptations to do something besides implement the policy that would produce the desired outcome, and yet do so by (d) deploying _technology، (or instruments) to bring about the desired change that are largely unknown ex ante. It is for precisely these types of development activities —and, importantly, elements of activities within more traditional technical sectors-that we propose PDIA as a pragmatic alternative.

\begin{tabular}{|l|l|l|}
\hline \multicolumn{2}{|c|}{ Table 1: Contrasting current approaches and PDIA } \\
\hline Elements of approach & $\begin{array}{l}\text { Mainstream Development } \\
\text { Projects/Policies/Programs }\end{array}$ & $\begin{array}{l}\text { Problem Driven } \\
\text { Iterative Adaptation }\end{array}$ \\
\hline What drives action? & $\begin{array}{l}\text { Externally nominated } \\
\text { problems or solutions' in } \\
\text { which deviation from_best } \\
\text { practice‘ forms is itself } \\
\text { defined as the problem }\end{array}$ & $\begin{array}{l}\text { Locally Problem } \\
\text { Driven-looking to solve } \\
\text { particular problems }\end{array}$ \\
\hline Planning for action & $\begin{array}{l}\text { Lots of advance planning, } \\
\text { articulating a plan of action, } \\
\text { with implementation } \\
\text { regarded as following the } \\
\text { planned script. }\end{array}$ & $\begin{array}{l}\text { = Muddling through' with } \\
\text { positive deviance and a } \\
\text { purposive crawl of the } \\
\text { available design space }\end{array}$ \\
\hline Feedback loops & $\begin{array}{l}\text { Monitoring (short loops, } \\
\text { focused on disbursement } \\
\text { and process compliance) } \\
\text { and Evaluation (long } \\
\text { feedback loop on outputs, } \\
\text { maybe outcomes) }\end{array}$ & $\begin{array}{l}\text { Tight feedback loops } \\
\text { based on the problem and } \\
\text { on experimentation with } \\
\text { information loops } \\
\text { integrated with decisions. }\end{array}$ \\
\hline $\begin{array}{l}\text { Top-down-the head learns } \\
\text { and leads, the rest listen and } \\
\text { follow. }\end{array}$ & $\begin{array}{l}\text { Diffusion of feasible } \\
\text { practice across } \\
\text { organizations and } \\
\text { communities of } \\
\text { practitioners }\end{array}$ \\
\hline
\end{tabular}

Finally, we wish to emphasize that our critique and approach share many similarities with other new approaches. For instance, Nancy Birdsall and the Center for Global Development have 
been promoting -Cash on Deliveryll (COD) aid (see Birdsall and Savedoff 2010). This is a mechanism by which donors would deliver resources to countries for achievements (versus a benchmark). This frees up the country to achieve those results however it wishes; rather than a focus on disbursement against planned inputs it would disburse against outcomes, however achieved. Similarly, there are new organizations like Innovations for Scaled Impact (iScale) ${ }^{21}$ that are based on very similar principles of bringing together local control over the problem nomination and definition stage with support to innovations built within tight feedback looks of evaluation and embedded in communities of practice. The World Bank itself is attempting support to various types of -results based financingll (see Brenzel 2009 on World Bank supported health projects) and the very recently introduced Program-for-Results lending.

\section{Conclusion}

This article is a follow up on our past work trying to explain the limited results of many efforts to build state capabilities in developing countries. This work's core argument is that the politics and processes of development interventions have fostered and exacerbated capability traps in many developing countries, wherein governments are being required to adopt best practice reforms that ultimately cannot work and end up crowding out alternative ideas and initiatives that may have emerged from local agents. Capability traps close the space for novelty, establishing fixed bestpractice agendas as the basis of evaluating developing countries and of granting organizations in these countries support and legitimacy if they comply with such agendas. In so doing they have all but excluded local agents from the process of building their own states, implicitly undermining the value-creating ideas of local leaders and front line workers. The upshot is unimplemented laws, unfunded agencies, and unused processes littering education sectors, public financial management regimes and judiciaries across the globe (Pritchett, Woolcock and Andrews 2010). Governments adopting such reforms look better for a period—when laws are newly passed, for instance — but ultimately they do not demonstrate higher levels of performance, as new laws are not put into practice.

\footnotetext{
${ }^{21}$ See www.scalingimpact.net (accessed February 13, 2012).
} 
Here we have suggested an approach that can help countries escape from the capability trap. It involves pursuing development interventions based on a very different set of principles. These interventions should (i) aim to solve particular problems in local contexts, (ii) through the creation of an authorizing environment that facilitates positive deviance and experimentation, (iii) involving active, ongoing and experiential learning and the iterative feedback of lessons into new solutions, and (iv) engaging broad sets of agents to ensure that reforms are viable, legitimate and relevant-i.e., politically supportable and practically implementable. We suggest that these four principles could be combined into a new way of doing development and state building, which we tentatively title Problem Driven Iterative Adaptation (PDIA). Our aim beyond this article is to use PDIA methods in particular interventions, and to gather accounts of where they may already have been introduced, the better to learn from the grounded experiences of others and to adapt/update/refine PDIA accordingly. As such it is an ongoing process to which we actively encourage readers to contribute.

\section{References}

Adler, D., Sage, C. \& Woolcock, M. (2009) Interim Institutions and the Development Process: Opening Spaces for Reform in Cambodia and Indonesia. Working Paper No. 86, Brooks World Poverty Institute, University of Manchester

Andrews, M. (2011). Which Organizational Attributes Are Amenable to External Reform? An Empirical Study of African Public Financial Management. International Public Management Journal 14(2), 131-156.

Andrews, M., McConnell, J., \& Wescott, A. (2008). Development as Leadership Led Change. Washington, D.C.: World Bank.

Baker, T., \& Nelson, R.E. (2005). Creating Something from Nothing: Resource Construction Through Entrepreneurial Bricolage. Administrative Science Quarterly, 50, 329-366.

Barzelay, M., \& R. Gallego. (2006). From -New Institutionalism\| to -Institutional Processualismll: Advancing Knowledge about Public Management Policy Change. Governance, 19(4), 531-557.

Birdsall, N. \& W. Savedoff (2010) Cash on Delivery: A New Approach to Foreign Aid. Washington, DC: Center for Global Development

Brenzel, L. (2009) Taking Stock: World Bank Experience with Results-Based Financing (RBF) for Health. Briefing Note, World Bank: Health, Nutrition and Population Unit. 
Booth, D. (2011). Aid Effectiveness: Bringing Country Ownership (and Politics) Back In. London: ODI Working Paper 336.

Brafman, O. \& Beckstrom, R. (2006). The Starfish and the Spider: The Unstoppable Power of Leaderless Organizations. New York: Portfolio.

Briggs, X. (2008). Democracy as Problem-Solving: Civic Capacity in Communities Across the Globe. Cambridge, MA: MIT Press.

Cameron, K.S. (1986). Effectiveness as Paradox: Consensus and Conflict in Conceptions of Organizational Effectiveness. Management Science, 32, 539-553.

Campbell, J.L. (2004). Institutional Change and Globalization. Princeton: Princeton University Press.

Carlile, P. R. \& Lakhani, K. R. (2011). Innovation and the Challenge of Novelty: The NoveltyConfirmation-Transformation Cycle in Software and Science. Harvard Business School Technology \& Operations Mgt. Unit Working Paper No. 11-096.

Chan, N. (2010). Narrative Change and Its Microfoundations: Problem Management, Strategic Manipulation, and Information Processing. Paper presented at the Workshop in Political Theory and Policy Analysis, Indiana University-Bloomington, 3 April 2010.

Dacin, M.T., Goodstein, J., \& Scott, W.R. (2002). Institutional Theory and Institutional Change: Introduction to the Special Research Forum. Academy of Management Journal, 45(1), 4557.

Denizer, C., Kaufmann, D. \& Kraay, A. (2011). Good Countries or Good Projects? Macro and Micro Correlates of World Bank Project Performance. Policy Research Working Paper No. 5646. Washington, DC: World Bank.

DiMaggio, P. \& W.W. Powell (1983) The Iron Cage Revisited: Institutional Isomorphism and Collective Rationality in Organizational Fields. American Sociological Review 48(April), 137-60.

Dorado, S. (2005). Institutional Entrepreneurship, Partaking, and Convening. Organization Studies, 26(3), 385-414.

Evans, P. (2004). Development as Institutional Change: The Pitfalls of Monocropping and Potentials of Deliberation. Studies in Comparative International Development, 38(4), 30-52.

Garud, R. \& Karnøe, P. (2003). Bricolage Versus Breakthrough: Distributed and Embedded

Agency in Technology Entrepreneurship. Research Policy, 32, 277-300. Greenwood, R., Suddaby, R., \& Hinings, C. R. (2002). Theorising Change: The Role of Professional Associations in the Transformation of Institutional Fields. Academy of Management Journal, 45(1), 58-80.

Grindle, M. (2004). Good enough governance: poverty reduction and reform in developing countries. Governance: An International Journal of Policy, Administration and Institutions, 17, 525-48.

Guldbrandsson, K., \& Fossum, B. (2009). An Exploration of the Theoretical Concepts Policy Windows and Policy Entrepreneurs at the Swedish Public Health Arena. Health Promotion International, 24(4), 434-444.

Heifetz, R. (1994). Leadership Without Easy Answers. Cambridge, MA: Harvard University Press.

Institute for Development Studies (2010). An Upside-Down View of Governance. Brighton: Centre for the Future State, Institute for Development Studies.

Ishikawa, K., \& Loftus, J.H. (1990). Introduction to Quality Control. Tokyo: 3A Corporation.

Jin,H.K., Kim, N., \& Srivastava, R.K. (1998). Market Orientation and Organizational Performance: Is Innovation a Missing Link? Journal of Marketing, 62, 30-45. 
Kenny, C. (2011). Getting Better: Why Global Development is Succeeding-And How We Can Improve the World Even More. New York: Basic Books.

Kingdon, J. W. (1995). Agendas, Alternatives, and Public Policies (2nd edition) New York: Harper Collins.

Knaus, G. (2011). The Rise and Fall of Liberal Imperialism, in R. Stewart and G. Knaus, Can Intervention Work? New York: Norton.

Levine, R. (2004) Millions Saved: Proven Successes in Global Health. Washington, DC: Center for Global Development.

Levy, B. \& Fukuyama, F. (2010) Development Strategies: Integrating Governance and Growth. Policy Research Working Paper No. 5196, Washington, World Bank.

Lindblom, C. (1959). The Science of „Muddling Through‘. Public Administration Review, 19, 79-88.

Mair, I. \& Marti, I. (2009). Entrepreneurship in and Around Institutional Voids: A Case Study From Bangladesh. Journal of Business Venturing, 24(5), 419-435.

Manzi, J. (2012). Uncontrolled: The Surprising Payoff of Trial-and-Error in Business, Politics and Society. New York: Basic Books.

Marsh, D., Schroeder, D., Dearden, K., Sternin, J. \& Sternin, M. (2004). The Power of Positive Deviance. British Medical Journal 329: 1177-1179.

McCay, B.J. (2002). Emergence of Institutions for the Commons: Contexts, Situations, and Events. In E. Ostrom (Ed.)., The Drama of the Commons. Washington, D.C.: National Research Council, 361-399.

Moore, M. (1995). Creating Public Value: Strategic Management in Government. Cambridge, MA: Harvard University Press.

Mukand, S. and Rodrik, D. (2005). In Search of the Holy Grail: Policy Convergence, Experimentation, and Economic Performance. American Economic Review, 95(1), 374383

Ostrom, E. (2005). Unlocking Public Entrepreneurship and Public Economies. WIDER Discussion Paper No. 2005/01. Helsinki: UNU/WIDER.

Ostrom, E. (2008). Design Principles of Robust Property-Rights Institutions: What have We Learned? In K.G. Ingram, and Y-H. Hong (Eds.). Property Rights and Land Policies. Cambridge, MA: Lincoln Institute of Land Policy, 25-51.

Pascale, R., Sternin, J. and Sternin, M. (2010). The Power of Positive Deviance: How Unlikely Innovators Solve the World's Toughest Problems. Harvard Business School Press.

PEFA. (2006). Public Expenditure and Financial Accountability (PEFA) Performance Measurement Framework. http://www.pefa.org/pfm_performance_file/the_framework_English_1193152901.pdf. Last accessed October 2009

Pires, R.R.C. (2011). Beyond the Fear of Discretion: Flexibility, Performance, and Accountability in the Management of Regulatory Bureaucracies. Regulation \& Governance, 5(1), 43-69.

Pritchett, L. (2011) Development as Experimentation (and How Experiments Can Play Some Role). Mimeo, Harvard Kennedy School.

Pritchett, L., Samji, S. \& Hammer, J. (2012) It‘s All About MeE: Learning in Development Projects through Monitoring (-M\|), Experiential Learning (-ell) and Impact Evaluation $(-\mathrm{E} \|)$. Center for Global Development Working Paper (forthcoming) 
Pritchett, L., \& Woolcock, M. (2004). Solutions when the Solution is the Problem: Arraying the Disarray in Development. World Development, 32 (2), 191-212.

Pritchett, L., Woolcock, M., \& Andrews, M. (2010). Capability Traps? The Mechanisms of Persistent Implementation Failure, Working Paper No. 234. Washington, DC: Center for Global Development.

Ridde, V. (2009). Policy Implementation in an African State: An Extension of Kindgon's Multiple-Streams Approach. Public Administration, 87 (4), 938-954.

Rodrik, D. (2008). Second-Best Institutions. American Economic Review: Papers and Proceedings, 98(2), 100-104.

Rondinelli, D. (1993). Development Projects as Policy Experiments: An Adaptive Approach to Development Administration. New York: Routledge.

Rose, R. (2003). What's Wrong with Best Practice Policies-And Why Relevant Practices Are Better. On Target? Government by Measurement. London: House of Commons Public Administration Select Committee HC 62-II, 2003, 307-317.

Senge, P. (1990 [2006]) The Fifth Discipline: The Art and Practice of the Learning Organization. New York: Doubleday.

Serrat, O. (2009). The Five Whys Technique. Asian Development Bank Knowledge Solutions, 30. Manila: Asian Development Bank.

Snow, D. A., \& Benford, R.D. (1992). Master Frames and Cycles of Protest. In A.D. Morris \& C. McClurg Mueller (Eds). Frontiers in Social Movement Theory. New Haven: Yale University Press, 133-155.

Sparrow, M. (2008). The Character of Harms: Operational Challenges in Control. New York: Cambridge University Press.

Van de Walle, N. (2001). African Economies and the Politics of Permanent Crisis, 1979-1999. New York: Cambridge University Press.

Whittle, A., Suhomlinova, O., \& Mueller, F. (2010). Dialogue and Distributed Agency in Institutional Transmission. Journal of Management \& Organization, 17 (4), 548-569.

Wong, K.C. (2011). Using an Ishikawa Diagram as a Tool to Assist Memory and Retrieval of Relevant Medical Cases from the Medical Literature. Journal of Medical Case Reports, 5, 120-123.

Zakocs, R.C. (2006). What Explains Community Coalition Effectiveness? American Journal of Preventive Medicine, 30(4), 351-361. 